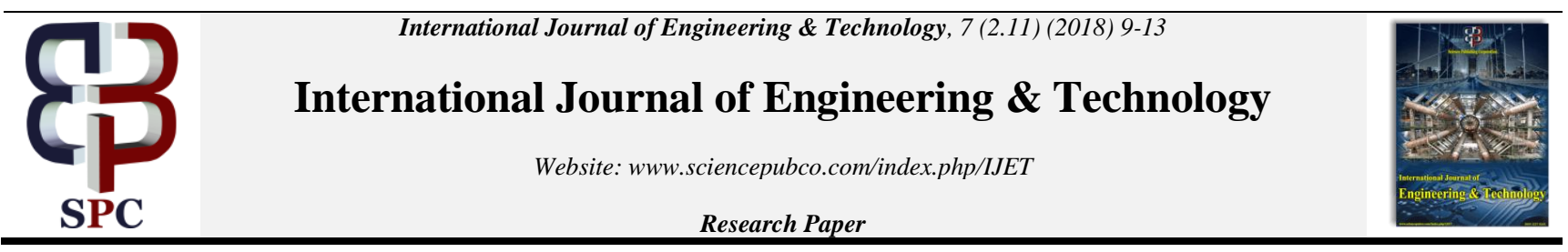

\title{
Harnessing Potentials of Social Media in Transforming Businesses
}

\author{
Loveleen Gaur ${ }^{1 *}$, Kumari Anshu² \\ ${ }^{1}$ Amity University, Noida, Uttar Pradesh, India \\ *Corresponding author E-mail: lgaur@amity.edu
}

\begin{abstract}
Media and technology has undergone radical transformation with time pertaining to change in requirements, technology up gradation, usefulness, using ease, accessibility etc. The main objective of mass media is to propagate facts and figures, generate consciousness and inform the community. Social media is regarded to be the subsequent prime revolution in the arena of communication. Social media is also an integral component of promotion and advertising campaigns, disseminating consciousness, marketing which is efficiently applied by startups and adept companies to generate a launching pad or stage for themselves. Progress in technology has enabled many businesses to reach mass or their fundamental customer base in no time and more effortlessly communicate with them which ultimately determine their goals and incline them towards buying judgments.
\end{abstract}

\section{Introduction}

The usage of social media is rising at an astronomical rate and there is no negation about the hegemony of social media and its influence on the business. The purpose of this paper is to study the role of social media in transforming business. Former to the advancements of social media, businesses counted on leaflets, brochures and advertising materials directed to the customers via e-mails, posts, television advertisements, conversations, chats etc. Although these publicizing strategies are still handy, businesses are nowadays using social media to promptly update shoppers about sales, latest product launch and selective deals and campaigns. Shoppers can also easily get associated with their preferred merchants online to stay up-to-date about the new advancements.

The manner in which social media has affected our lives both personally as well as professionally is way bigger and larger than many of us could have expected. Social media impels people to express and share their understanding, thoughts and assessments with others. It is about engaging people to interact with each other. The evolution of social media over the past five to ten years has been significant. $92 \%$ of marketers believe that harmonizing with social media is crucial for their businesses, it's undoubted that marketers have developed trust and confidence in social media [1].

Social media offers a distinctive prospect for business to remain on top of mind of the existing customers and get on the senses of the prospects. $70 \%$ of dealers discovered that social media events enhanced tread to their website whereas $75 \%$ of businesses involved in social media events over a year or more claimed a more substantial increment in the footfall.

It is well known that in most of the cases users get engrossed on social platforms for individual prerequisites firstly. Busi-
ness2Business marketing, time and again encompasses various assessment making at various points in the buying process. Opportunely, social platforms are initiating to craft an atmosphere convenient for dealers to target shoppers as per their likings, nature of work and demographics. It unlocks the gate for Business2Business dealers to tailor made customized messages as per the requirements.

Marketers fell that social media helps to get market understanding that they were not having before or restated what they were already knowing by this time. Social media facilitates business to view the customers in their actual settings. It is easy to unearth whom are they interacting with, their favored movies, television programs, job profile, interests and to an unending list of activities.

More than 50\% marketers have been using social media for years are generating leads through social media. In order to develop competent information through social media, masses have to develop reliance in the business, get engaged and exhibit a need generated for the offer.

Few web-based social networks of buying behavior related social media applications:

- Social Networking Sites- It helps purchasers to interface by creating individual data profiles, getting friends to have access to those profiles, and sharing messages, texts [1]. They are the most out reached and percolating example of online networking and there eminence is increasing throughout the world. Facebook, Google+ and LinkedIn are the most important cases of SNS [2]\}

- Blogs- It depicts an individual site or reliably overhauled sections, primarily consisting of content, pictures, recordings and connections to different sites [3]. 
- Content Communities-These are online applications that enable clients to share media stuff, for instance, recordings, photographs, documents, presentations, music and web joins. YouTube, Instagram, Flickr and Picasa are relevant examples. YouTube and Instagram is the most popular of all substance groups [4].

- Consumer survey sites or Consumer review sites (CRW) are online networking applications. It enable clients to transfer item related surveys and evaluations. It offers variety of features, from sharing comments and pictures, and from an item or administration rating on a solitary variable, to an important scope of components, for example, lists of things to get, value examinations, propelled seek, multi variable appraisals, value correlations, value history outlines, purchase/hold proposals, value cautions, arrangements' rankings, vendor/retailers' assessments, customized shopping and that's only the tip of the iceberg [5].

\section{Literature Review}

According to [6] social media allows customers to share data, facts and figures with their friends and colleagues regarding the merchandise and service brands. Such discussions among these groups offer companies an alternative, cost efficient technique to intensify brand consciousness, pep up association with brand and recall, and intensify brand reliability and loyalty [7].

Study shows that providing pertinent and updated content is an essential strategy to thrive a product's brand on social media effectively. Acceptance and appreciation of the social media and the content among peers is an additional vital purpose for the consumers to be involved with brands on social media [8]. As there are numerous social media platforms and it is difficult to encompass in each and every one, dealers should explore their customer segment and select to join in the most appropriate medium to connect to them. Also, given that smart phone applications permit clients to associate with the brand and build brand loyalty [9].

It is established that internet is typical and unique, have competencies to transform, create a channel, and also own the capacity to construct a bridge for people with similar likings, principles, beliefs and principles that could boost assertiveness and self-confidence[10].

The paper considered the impact of digital media. They lastly concluded that variation is continuous in digital media. Newer channels are evolving and getting added to prevailing formats [11].

The white paper implemented an observational study method to scrutinize the complicated and multi-faceted nature of social media. Major emphasis was on the advances of social media facilities, and considers that their outcome for surveillance studies [12].

Shoppers are segregating from the old-style of advertising through radio, television, magazines, and newspapers. They are also steadily demanding more power and ability to choose over their media consumption. They want on-demand and prompt admittance to information and evidences at their own suitability [13].

Shoppers are relying more often on different types of social media to carry on their information searches and to decide on their buying choices [14].

Social media is observed by customers as a more dependable foundation of evidence regarding products and services than company-sponsored information conveyed via the timeworn components of the promotion mix [15].

\section{Research Work}

\subsection{Objectives}

1. Analyze the impact of social media on businesses in current scenario.
2. Explore the emerging business opportunities with the advent of social media.

3. Develop the framework for harnessing social media's potential in businesses.

\subsection{Research Methodology}

The study has been intended with a combination of qualitative and quantitative work. Research papers have been considered for carrying out the Qualitative study. Structured survey were carried out of the respondents for the Quantitative study to comprehend the influence of social media on business and trade. Structured questionnaire were collected from 157 respondents with their opinions by conducting interviews. The questionnaire majorly comprised of likert and rank order scale questions on their business opportune and marketing proficiency provided by social media.

\subsubsection{Framework}

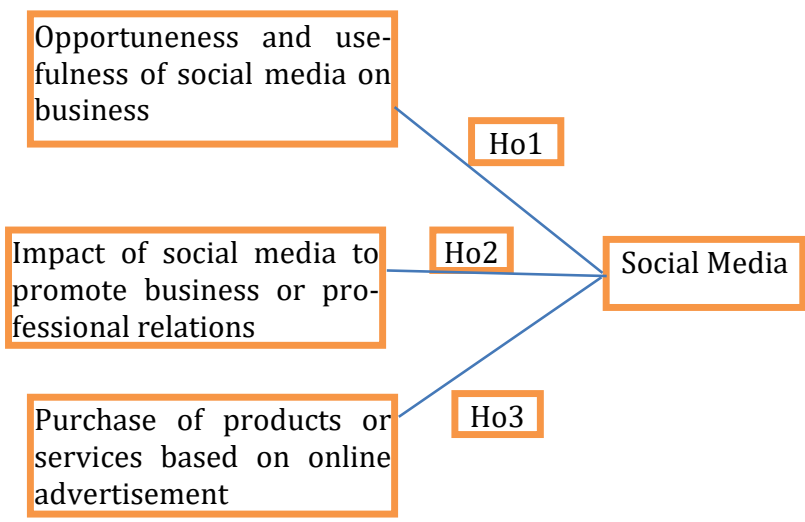

Fig. 1. Frame work for Hypothesis Testing

\subsubsection{Hypothesis}

1. Ho1: Opportuneness and usefulness of social media on business.

2. Ho2: Impact of social media to promote business or professional relations.

3. Ho3: Purchase of products or services based on online advertisement.

\section{Analysis and Interpretation}

The study covers a prime research directed on 157 respondents amongst whom the mix of males and females is in the ratio of 4:3 (Table 1). Responses are collected from respondents in urban area and it comprises of $25.5 \%$ students and $74.4 \%$ were working, engaged either in services or business.

Table 1. Respondents Profile

\begin{tabular}{cccc}
\hline \multicolumn{2}{c}{ Variable } & Frequency & Percent \\
\hline \multirow{4}{*}{ Age group } & $18-21 \mathrm{yrs}$ & 10 & 6.4 \\
& $22-25 \mathrm{yrs}$ & 37 & 23.6 \\
& $26-29 \mathrm{yrs}$ & 93 & 59.2 \\
& $42-45 \mathrm{yrs}$ & 17 & 10.8 \\
& Service & 64 & 40.7 \\
Occupation & Business & 53 & 33.7 \\
& Student & 40 & 25.5 \\
& Male & 90 & 57.3 \\
& Female & 67 & 42.6 \\
\hline
\end{tabular}




\subsection{Testing of Hypothesis}

Ho1: Opportuneness and usefulness of social media on business Analyzing the information obtained from the respondents we obtain a model summary (Table 2), by applying multiple regression. The value of adjusted $\mathrm{R}$ square is 0.421 . This explains that $42.1 \%$ of the changes in social media is considered very convenient and useful for business is explained by change in dependent variables. The significance level is also $<.05$ and $F$ value is 39.76 . Thus we can conclude from the analysis that social media is considered useful and full of Opportunities for business. Therefore the Null Hypothesis is accepted.

Table 2. Summary of analysis for Opportuneness and usefulness of social media on business

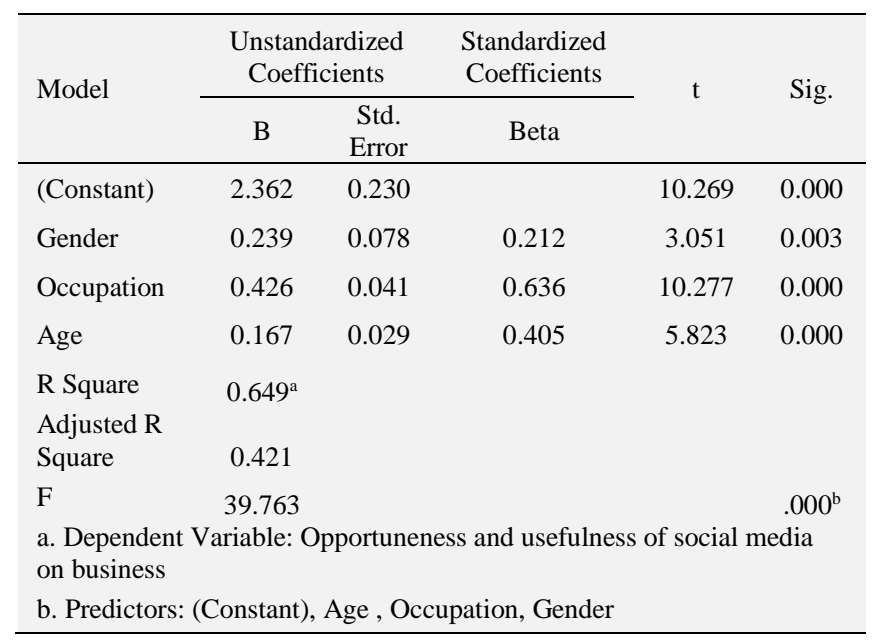

$$
Y=a+b_{1} X_{1}+b_{2} X_{2}+b_{3} X_{3}
$$

$\mathrm{Y}=2.362+0.239($ Gender $)+0.426($ Occupation $)+0.167($ Age $)$

This equation shows the impact of the various independent variables on the predictable value of the dependent variable i.e. Opportuneness and usefulness of social media on business. It is established from the study that people are gradually becoming more amicable towards social media. They are realizing and learning the usage of social media for different purposes including business and at the same time finding it very opportunistic, convenient and useful. They are now becoming habituated to social media.

They are connecting social media with business for reaping the benefits of increased brand exposure to a wider range of audience. Thus helping the business to have in depth and penetrating insight of the marketplace. There is also an increase in website traffic which further generates leads for future business. At most care should be taken by the business for respondent's pressing concerns for speed, privacy and security.

Ho2: Impact of social media to promote business or professional relations

Analyzing the information obtained from the respondents we obtain a model summary (Table 3), by applying multiple regression. The value of adjusted $\mathrm{R}$ square is 0.489 . This explains that $48.9 \%$ of the changes in impact of social media to promote business or professional relations is explained by change in dependent variables. The significance level is also $<.05$ and $\mathrm{F}$ value is 52.39 . Thus we can interpret from the analysis that Social media has an impact on promoting business or professional relations. Therefore the Null Hypothesis is accepted.
Table 3. Summary of analysis for Impact of social media to promote business or professional relations

\begin{tabular}{|c|c|c|c|c|c|}
\hline \multirow{2}{*}{ Model } & \multicolumn{2}{|c|}{$\begin{array}{l}\text { Unstandardized } \\
\text { Coefficients }\end{array}$} & \multirow{2}{*}{$\begin{array}{c}\begin{array}{c}\text { Standardized } \\
\text { Coefficients }\end{array} \\
\text { Beta }\end{array}$} & \multirow{2}{*}{$\mathrm{t}$} & \multirow{2}{*}{ Sig. } \\
\hline & B & $\begin{array}{l}\text { Std. } \\
\text { Error }\end{array}$ & & & \\
\hline (Constant) & 1.699 & 0.159 & & 10.697 & 0.000 \\
\hline Gender & -0.435 & 0.054 & -0.524 & -8.020 & 0.000 \\
\hline Occupation & 0.207 & 0.029 & 0.421 & 7.245 & 0.000 \\
\hline Age & -0.086 & 0.020 & -0.284 & -4.345 & 0.000 \\
\hline $\begin{array}{l}\text { R Square } \\
\text { Adjusted R }\end{array}$ & $0.700^{\mathrm{a}}$ & & & & \\
\hline Square & 0.489 & & & & \\
\hline $\mathrm{F}$ & 52.399 & & & & $.000^{\mathrm{b}}$ \\
\hline
\end{tabular}

a. Dependent Variable: Impact of social media to promote business or professional relations.

b. Predictors: (Constant), Age, Occupation, Gender

$$
\begin{aligned}
& \mathrm{Y}=\mathrm{a}+\mathrm{b}_{1} \mathrm{X}_{1}+\mathrm{b}_{2} \mathrm{X}_{2}+\mathrm{b}_{3} \mathrm{X}_{3} \\
& \mathrm{Y}=1.699+(-)) 0.435(\text { Gender })+0.207(\text { Occupation })+(-) \\
& 0.086(\text { Age })
\end{aligned}
$$

This equation shows the impact of the various independent variables on the predictable value of the dependent variable i.e. impact of social media to promote business or professional relations. Studies reveal that social media has an impact on developing skills, confidence, learning and career building. The social networking sites help bringing people with similar cause and business orientation together and help in many startup business to flourish. Business should keep a tap and study the social and cultural groups to which the consumers is connected and strategize the Social media marketing plans as per the understandings developed. Social media is a relatively less costly marketing tool, the best of Social media marketing plan for the company would be aiming buyers prior to understanding their social behavior and designing relevant content which offers some advantageous benefits to the buyers on frequent basis at all the available social media platforms to generate business and ultimately brand loyalty.

Ho3: Purchase of product or service based on an online advertisement

Analyzing the information obtained from the respondents we obtain a model summary (Table 4), by applying multiple regression. The value of adjusted $\mathrm{R}$ square is 0.255 . This explains that $25.5 \%$ of the changes in purchase of product or service based on an online advertisement is explained by change in dependent variables. The significance level is also $<.05$ and $F$ value is 18.753 . Thus we can interpret from the analysis that purchase of product or service are not based on an online advertisement. Therefore the Null Hypothesis is rejected.

$$
\mathrm{Y}=\mathrm{a}+\mathrm{b}_{1} \mathrm{X}_{1}+\mathrm{b}_{2} \mathrm{X}_{2}+\mathrm{b}_{3} \mathrm{X}_{3}
$$

$\mathrm{Y}=1.304+(-) 0.092($ Gender $)+(-) 0.144($ Occupation $)+0.118$

(Age)

This equation shows the impact of the various independent variables on the predictable value of the dependent variable i.e. purchase of product or service based on an online advertisement. Social media is bringing about a shift in the mode people receive communications. As an alternative of information being distributed from a source, the shoppers are generating it on their own. Initial shopper's experiences are being noted and this becomes the foundation of consumer's preference information later on. People who are regularly using different social media channels are increasing and are getting more and more intertwined with social media to propagate their businesses and to develop associations with others. It is amongst the most convenient, minimum cost incurring, and most operational ways to gain publicity and to reinforce the business's repute. People prefer emails and social media the most among the numerous modes of getting exposure to adver- 
tisement. Gap is also found between shoppers becoming open to social media commercials and making tangible purchase choices based on these commercials. These gaps are intermediate and will bridge in due course of time.

Table 4. Summary of analysis for Purchase of products or services based on online advertisement

\begin{tabular}{|c|c|c|c|c|c|}
\hline \multirow[t]{2}{*}{ Model } & \multicolumn{2}{|c|}{$\begin{array}{l}\text { Unstandardized } \\
\text { Coefficients }\end{array}$} & \multirow{2}{*}{$\begin{array}{c}\begin{array}{c}\text { Standard- } \\
\text { ized Co- } \\
\text { efficients }\end{array} \\
\text { Beta }\end{array}$} & \multirow[t]{2}{*}{$\mathrm{t}$} & \multirow[t]{2}{*}{ Sig. } \\
\hline & B & $\begin{array}{c}\text { Std. } \\
\text { Error }\end{array}$ & & & \\
\hline (Constant) & 1.304 & 0.211 & & $\begin{array}{c}6.17 \\
4\end{array}$ & 0.000 \\
\hline Gender & 0.092 & 0.072 & -0.101 & $\begin{array}{c}- \\
1.27 \\
7\end{array}$ & 0.000 \\
\hline Occupation & $0 . \overline{144}$ & 0.038 & -0.265 & $\begin{array}{c}- \\
3.78 \\
2\end{array}$ & 0.000 \\
\hline Age & 0.118 & 0.026 & 0.352 & $\begin{array}{c}4.46 \\
5\end{array}$ & 0.000 \\
\hline R Square & $\underset{\mathrm{a}}{0.505}$ & & & & \\
\hline $\begin{array}{l}\text { Adjusted R } \\
\text { Square }\end{array}$ & 0.255 & & & & \\
\hline $\mathrm{F}$ & $\begin{array}{c}18.75 \\
3\end{array}$ & & & & $.000^{\mathrm{b}}$ \\
\hline \multicolumn{6}{|c|}{$\begin{array}{l}\text { a. Dependent Variable: Purchase of product or service based on } \\
\text { online advertisement. }\end{array}$} \\
\hline b. Predictor & onstant & Age, Oc & pation, Ger & & \\
\hline
\end{tabular}

\section{Findings}

It is proven from the research aftermaths that social media has developed as an essential and inseparable part of people's life. They are getting accustomed to social media and getting involved in it expansively for social networking, linking with new people, carrying out business. It has collapsed the world boundaries, minimized the communication barriers and produced de-centralized communication and businesses, connecting distant people. Social media impacts skills, confidence, learning and career development among people. The social networking sites help bringing people with similar skills and business orientations together. Social media is a relatively less costly marketing tool and convenes an unobstructed flow of information to build upon the information.

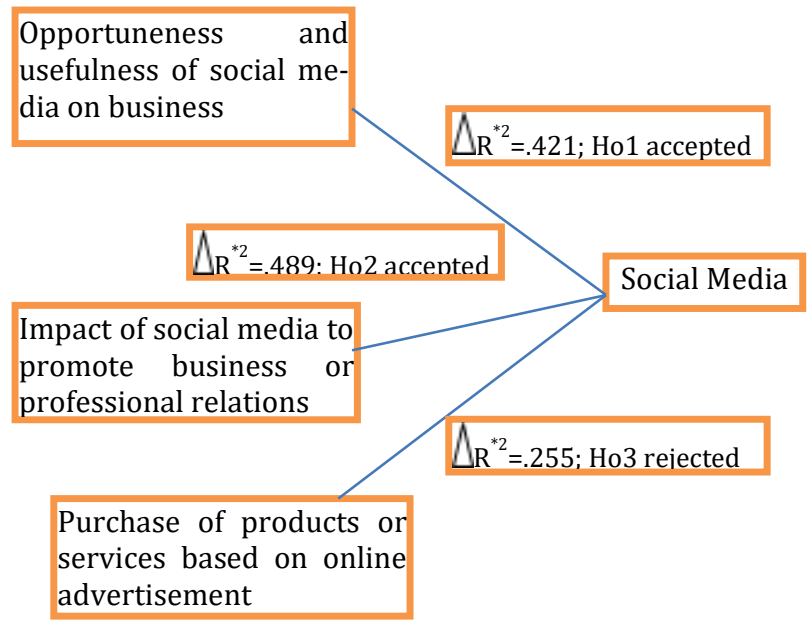

Fig. 6. Frame work with results Hypothesis testing

Social media is connected with business for reaping the benefits of increased brand exposure to have a deeper insight of the marketplace. There is also an increase in website traffic and lead generation for future business. Progressively people are getting more amenable and accessible towards social me- dia promotion. They are discovering these social media commercials beneficial, which is profiting the business as well as the people in generating brand consciousness. Nevertheless at the same time it was found that there is still a gap between people getting exposed to these advertisements and actually becoming consumer of that brand. These gaps are expected to eliminate slowly and steadily with the passage of time.

\section{Conclusion}

The application of social media intends to improve the masses insight, degree of openness in communication, and to construct robust association in people and amid people and business. It has casted a profound influence on our society and has affected people of diverse age groups. Social media site have not only emerged as an entertainment source but also as significant platform for doing business. Ultimately all social media activity is to be custom-made to redirect the target audience with respect to commerce set-up and useful information and connectivity in case of individuals.

Social media has also been a vital part of promotional drives, spreading awareness, publicity which is efficiently applied by adept companies and startups to create a stage for them. Progresses in technology has enabled many business to reach mass or their strategic audiences in no time and more effortlessly convey the communications which ultimately drive their objectives and lead them to make buying assessments. Advertising on social media definitely provides access to more people but it doesn't change the quality of the message. So, to get the maximum out of social media advertising the business should consider creating clear and concise messages with strong visual assets. Also apply platform targeting features and changing ads frequently to avoid ad fatigue. Advertisements should also be designed with mobile users in mind. Understanding the consumers and the social media sites they engage with is very important to get a real sense of how to position messages for each platform. For instance the way that most users network on LinkedIn is very unlike than they would use an Instagram account.

Business should study the social and cultural groups of the consumers to which they are connected and strategize plans harnessing social media potential with businesses. Company should try aiming buyers to understand their social behaviour and designing relevant content which offers some advantageous benefits to the buyers on frequent basis at all the available social media platforms to generate business and ultimately develop brand loyalty.

\section{References}

[1] Zeckman, A. (2015). New Report Reveals the True Impact of Social Media Marketing for Business.

[2] Casado, N. S., Navarro, J. G., Wensley, A., \& Solano, E. T. (2016). Social networking sites as a learning tool. The Learning Organization 23, 23 - 42.

[3] Zarkada, A. K., \& Polydorou, C. (2014). You Might be Reputable but are you "Liked"? Orchestrating Corporate Reputation Co-Creation on Facebook. Social Media in Strategic Management 11, 87-113.

[4] Hsun Ho, C., Hui Chiu, K., Chen, H., \& Papazafeiropoulou, A. (2015). Can internet blogs be used as an effective advertising tool? The role of product blog type and brand awareness. Journal of Enterprise Information Management , 28 (3), 346 - 362.

[5] Anderson, K. E. (2016). Getting acquainted with social networks and apps: Instagram's instant appeal. Library Hi Tech News , 33 (3), $11-15$.

[6] Stileman, P. (2009). To what extent has social media changed the relationship between brand and consumer? Dissertation of MA Advertising, Bucks New University.

[7] Genelius, S. (2011). 30 minute social media marketing: step by step techniques to spread the words about your business. USA: McGraw-Hill. 
[8] Brito, M. (2011). Reasons Why Relevant Content Matters, retrieved from http://www.socialmediaexplorer.com/socialmediamarketing/3-reasons-why-relevant-content-matters/.

[9] Kim, D. A. (2011). Students use of hotel mobile apps: their affects of brand loyalty. http://scholarworks.umass.edu/cgi/viewcontent.cgi? article $=1242$ \& context=gradconf_hospitality

[10] McKenna, J. A. (2004). The Internet and the Social Life. . www.uvm.edu/pdodds/files/papers/others/2004/bargh2004a.pdf.

[11] Jonny Bentwood, E. (2007). Distributed Influence: Quantifying the Impact of Social Media. https://technobabble2dot0.wordpress.com/2008/01/16/whitepaper-distributed-influence-quantifying-the-impact-of-socialmedia/

[12] Trottier., D. (2012). Social Media As Surveillance: Rethinking Visibility. Ashgate Publishing.

[13] Vollmer, C. \&. (2008). Always on: Advertising, marketing, and media in an era of consumer control. New York: McGraw-Hill

[14] Lempert, P. (. (2006). Caught in the Web. Progressive Grocer, 85(12), 18.

[15] Foux, G. (. (2006). Consumer-generated media: Get your customers involved. Brand Strategy , 38-39. 